\title{
MODEL SEJARAH DAN POLA PENDIDIKAN ISLAM PADA MASA RASULULLAH SAW DAN IMPLEMENTASINYA
}

\author{
Indah Khozinatun Nur \\ Email: indahkhozinatun@gmail.com \\ SD Negeri Mranggen 2 Kabupaten Demak \\ Jalan Kauman No. 103 Mranggen Demak Jawa Tengah
}

\begin{abstract}
ABSTRAK
Penelitian ini menggunakan penelitian kualitatif dengan jenis library research. Penelitian ini bertujuan mendeskripsikan pola pendidikan Islam pada masa Rasulullah Saw, sebagai rujukan dan pijakan dalam melaksanakan pendidikan pada masa kini dan masa yang akan datang, agar normanorma dan nilai-nilai ajaran Islam tetap utuh. Hasil penelitian menunjukkan bahwa antara pendidikan Islam yang diajarkan oleh Nabi Muhammad Saw. di Makkah dan Madinah memiliki karakter, pola, dan perkembangannya yang berbeda. Di Makkah lebih kepada pengajaran pendidikan Islam yang menekankan pada pemahaman tauhid dan pengajaran alquran, sedangkan di Madinah lebih meluas cakupannya yakni selain diajarkan tauhid dan alquran, masyarakat Madinah dibekali dengan pendidikan akhlak, amal ibadah, kehidupan sosial kemasyarakatan dan keagamaan, ekonomi, kesehatan, bahkan kehidupan bernegara.
\end{abstract}

Kata kunci: pendidikan Islam, masa Rasulullah Saw

\begin{abstract}
This research uses qualitative research with library research type. This study aims to describe the pattern of Islamic education at the time of the Prophet Muhammad, as a reference and foothold in carrying out education in the present and in the future, so that the norms and values of Islamic teachings remain intact. The results showed that between Islamic education taught by the Prophet Muhammad. in Mecca and Medina have a different character, pattern, and development. In Makkah it is more to teach Islamic education which emphasizes the understanding of monotheism and the teaching of the Koran, while in Madinah it is more broad in scope, namely in addition to being taught monotheism and the Koran, the people of Madinah are provided with moral education, charity work, social and religious life, economy, health, and even state life.
\end{abstract}

Keywords: Islamic education, the time of the Prophet Muhammad 


\section{PENDAHULUAN}

Pengetahuan tentang sejarah merupakan hal yang penting untuk dijadikan pijakan dalam kehidupan, tak terkecuali sejarah pendidikan Islam. Bagi umat Islam memahami tentang sejarah pendidikan Islam sangat bermanfaat dalam rangka meneladani proses pendidikan sejak zaman Rasulullah Saw. Dengan demikian umat Islam bisa mengetahui dan memahami bagaimana perkembangan pendidikan Islam dari masa-ke masa sehingga bias menjadi solusi pemecahan masalah dan problematika pendidikan Islam saat ini.

Islam menempatkan pendidikan pada kedudukan yang penting dan tinggi dalam doktrin Islam. Ahmad Tafsir menyatakan bahwa pendidikan dalam Islam merupakan rangkaian proses pemberdayaan manusia menuju taklif (pendewasaan), baik secara akal, mental maupun moral untuk menjalankan fungsi kemanusiaan yang diemban sebagai seorang hamba (abd) di hadapan khaliqnya dan sebagai pemelihara (khalifah) pada semesta (Tafsir, 1994). Pendidikan merupakan komponen penting dalam dalam kehidupan yang mampu membentuk peradaban manusia.

Proses pendidikan sebenarnya telah berlangsung sepanjang sejarah dan berkembang sejalan dengan perkembangan sosial budaya manusia di bumi. Begitu pula dengan pendidikan Islam yang pertama kali diajarkan oleh Rasulullah dengan berbagai hambatan dan pertentangan dari orang-orang yang tidak mempercayai dan menentang ajaran Islam.

Kajian tentang pendidikan Islam pada masa Rasulullah Saw penting untuk ditelaah kembali sebagai rujukan dan pijakan dalam melaksanakan pendidikan pada masa kini dan masa yang akan datang, agar norma-norma dan nilai-nilai ajaran Islam tetap utuh. Hal ini dikarenakan figur Rasulullah Saw sebagai pendidik atau guru merupakan acuan dan panduan bagi umat Islam dalam melaksanakan pendidikan.

\section{METODE PENELITIAN}

Penelitian ini merupakan jenis penelitian kualitatif yang datanya diperoleh melalui sumber literer (library research). Pengumpulan data dilakukan dengan metode dokumntasi. Metode dokumentasi adalah teknik atau cara mengumpulkan data melalui peninggalan tertulis berupa arsip-arsip dan termasuk juga buku-buku tentang pendapat, teori, dalil atau hokum-hukum dan lain-lain yang berhubungan dengan masalah penelitian (Muhajir, 1996: 49).

\section{PEMBAHASAN DAN HASIL}

\section{Kondisi Jazirah Arab sebelum Islam}

Kondisi kehidupan bangsa Arab sebelum datangnya agama Islam ada dalam keadaan yang memprihatinkan. Hal ini banyak digambarkan dalam Al-Qur'an dengan ungkapan-ungakapan negatif seperti al-jahiliyah yang berarti dalam keadaan bodoh (QS. Al-Maidah: 50), dzulumat yang berarti berbuat durhaka mengabaikan perintah Tuhan dan melanggar larangan-Nya (QS. Al-Baqarah: 257), fasad yang berarti berbuat kerusakan di muka bumi (QS. Ar-Rum: 41), a'da'an yang berarti bermusuhan (QS. Ali Imran: 103) dan fi dlalal-al mubin yang artinya dalam kesesatan yang nyata (QS. Ali Imran: 164).

Gambaran dalam al Qur'an tentang kondisi kehidupan bangsa Arab sebelum kehadiran Islam menunjukkan ada sesuatu yang rusak dalam segala aspek kehidupan mereka. Kerusakan tersebut terlihat dalam aspek akidah, ibadah dan akhlak yang selanjutnya berpengaruh terhadap rusaknya system ekonomi, social, politik, budaya, hokum dan pendidikan

Dari aspek akidah, Masyarakat Arab sebelum Islam adalah masyarakat yang hidup di zaman Jahiliyyah dimana mereka tidak mengenal agama tauhid sehingga moralitasnya sangat minim. Masyarakat Arab saat itu tidak mempercayai Allah Swt tetapi sebaliknya mereka mempercayai bendabenda atau segala sesuatu selain Allah. Mereka meyakini bahwa berhala yeng mereka sembah bias memberikan perlindungan keselamatan hidup mereka. Kepercayaan kepada selain Allah merupakan kekeliruan yang sangat besar.

Aspek ibadah, masyarakat Arab menyembah berhala yang mereka buat sendiri. Mereka telah keliru dan tersesat dalam menggunakan akal sehatnya. Menyembah dan memuja segala sesuatu yang sesungguhnya tidak mampu mendatangkan manfaat atau menolak mudarat. Ratusan berhala ditempatkan disekitar ka'bah untuk disembah. Masyarakat yang sudah sangat sesat terutama dalam sisi akidah, mereka telah menyimpang jauh dari fitrah Iman-Islam mereka sehingga terjebak dalam penyekutuan Allah, yakni bergelimang dalam kemusyrikan. Tidak kurang dari 360 berhala yang disembah oleh mereka sempat mengotori kesucian Baitullah, Kabah

Aspek akhlak, keadaan masyarakat saat itu sangat tidak terkendali karena tidak adanya peraturan yang mengakibatkan mereka berbuat seenaknya sendiri. Masyarakat Jahiliyah juga 
ditandai dengan keberadaan orang-orang yang malas bekerja yang tidak mau berusaha, mereka lebih senang menggantungkan nasibnya lewat berjudi, karena itu akrablah kehidupan mereka juga dengan kebiasaan minum khamr. Konon, judi dan khamr ini merupakan dua sejoli yang sangat bersahabat, karena biasanya para penjudi itu juga adalah peminum. Pada masa Jahiliyah, wanita hampir tidak ada nilainya di mata kaum pria, Kegiatan-kegiatan buruk mereka lakukan, mulai dari berjudi, mencela keturunan, mengubur hidup-hidup anak perempuan, serta menghina dan mencela orang miskin dan lemah. Moral dan perilaku masyarakat Arab yang busuk dan rusak inilah yang menjadikan mereka disebut sebagai kaum jahiliyah.

Kehadiran Islam dengan diutusnya Nabi Muhammad Saw sebagai Rasul membawa perubahan besar pada masyarakat jazirah Arab saat itu. Perjalanan Nabi Muhammad dalam penyampaian dakwah dan pendidikan Islam pada saat itu sangat berat. Beliau melalui proses panjang dan ujian yang berat baik dari dalam dan luar kaumnya sendiri. Namun perjuangan Nabi Muhammad terbayarkan dengan berhasil membangun pondasi kuat agama Islam di tanah Arab. Dalam pembinaan pendidikan Islam Nabi Muhammad terdiri dari dua fase yaitu: (1) Fase Makkah yakni fase awal pembinaan pendidikan Islam dan (2) Fase Madinah yakni fase penyempurnaan pendidikan Islam.

\section{Pendidikan di Mekkah}

Sebelum nabi Muhammad Saw memulai tugasnya sebagai Rasul, yaitu melaksanakan pendidikan Islam terhadap umatnya, Allah Swt telah mendidik dan mempersiapkan beliau untuk melaksanakan tugas tersebut secara sempurna. Pelaksanaan pendidikan pada masa Rasulullah berdasarkan petunjuk dan bimbingan langsung dari Allah SWT. Rasulullah menerima petunjuk atau wahyu dari Allah dan menyampaikannya kepada ummatnya agar kumpulan dan wahyu-wahyu tersebut diterima dan dijadikan sebagai kehidupan yang tak terpisahkan dari ummatnya.

Nabi Muhammad Saw menerima wahyu yang pertama di Gua Hira di Makkah pada tahun 610 M. Wahyu yang merupakan petunjuk dan instruksi dari Allah untuk melaksanakan tugas kerasulannya itu termaktub ayat Alquran surat al 'alaq: 1-5 yang artinya: "Bacalah dengan (menyebut) nama Tuhanmu yang menciptakan. Dia telah menciptakan manusia dari segumpal darah. Bacalah, dan Tuhanmulah yang Maha Mulia. Yang mengajarkan (manusia) dengan pena. Dia mengajarkan manusia apa yang belum diketahuinya.

Kemudian disusul oleh wahyu yang kedua yaitu Al quran surah al Mudatsir ayat 1-5 yang artinya: Hai orang yang berkemul (berselimut). Bangunlah, lalu berilah peringatan! dan agungkanlah Tuhanmu! dan bersihkanlah pakaianmu. dan tinggalkanlah segala (perbuatan) yang keji. dan janganlah kamu memberi (dengan maksud) memperoleh (balasan) yang lebih banyak. Dan karena Tuhanmu, bersabarlah.

Dengan turunnya wahyu itu Nabi Muhammad SAW telah diberi tugas oleh Allah, supaya bangun melemparkan kain selimut dan menyingsingkan lengan baju untuk memberi peringatan dan pengajaran kepada seluruh umat manusia, sebagai tugas suci, tugas mendidik dan mengajarkan Islam. Kemudian kedua wahyu itu diikuti oleh wahyu-wahyu yang lain. Semuanya itu disampaikan dan diajarkan oleh Nabi, mula-mula kepada karib kerabatnya dan teman sejawatnya dengan sembunyi-sembunyi.

Isi ajaran-ajaran yang disampaiakan oleh Rasulullah SAW di awal kenabiannya adalah tentang Keesaan Allah SWT, Hari Kiamat sebagai hari pembalasan, Kesucian jiwa dan persaudaraan dan persatuan. Tujuan dakwah Rasulullah SAW pada periode Mekah adalah agar masyarakat Arab mampu meninggalkan kejahiliyannya dalam bidang agama, moral dan hukum. Sehingga menjadi umat yang mempercayai kebenaran utusan Allah SWT dan ajaran agama Islam yang disampaikannya sekaligus agar dapat mengamalkannya dalam kehidupan sehari-hari.

\section{a. Materi Pokok Pendidikan Islam}

Hanun sebagaimana dikutip Abdul Kodir (2015:38) menyebutkan ada dua bidang pokok dalam pendidikan Islam yang dilakukan nabi Muhammad Saw di kota Mekkah adalah pendidikan tauhid dan pengajaran al Qur'an.

Aqidah atau keyakinan merupakan unsur rohani manusia yang paling besar perannya dan banyak mengeluarkan instruksi kepada anggota jasmani untuk melakukan suatu perbuatan. Aqidah yang benar akan membuahkan aktifitas manusia yang benar, akan tetapi kalau sudah salah, maka perbuatan manusia yang ditimbulkannya menjadi salah pula. Akhlaqul Karimah mempunyai peranan yang penting dalam mewujudkan ketertiban dan keharmonisan aktifitas kehidupan manusia. Oleh karena itu usaha ke arah perbaikan akhlak merupakan kebutuhan pokok yang harus dilaksanakan oleh setiap individu, rumah tangga dan masyarakat, bangsa dan Negara. Oleh karena itu 
aqidah Islam mempunyai peranan yang sangat besar terhadap pendidikan dan perbaikan akhlak manusia agar memiliki akhlak yang mulia.

1) Pendidikan Tauhid

Pendidikan tauhid ini merupakan intisari pendidikan Islam di kota Mekkah yang menjadi perhatian utama nabi Muhammad mengingat pada saat itu masyarakat jahiliyyah banyak menyimpang dari ajaran tauhid yang telah dibawa oleh nabi Ibrahim as. Pendidikan tauhid ini menitikberatkan pada penanaman nilai-nilai tauhid ke dalam jiwa setiap individu muslim agar dalam jiwa mereka terpancar sinar tauhid dan tercermin dalam perbuatan dan tingkah laku sehari-hari.

Pokok-pokok ajaran tauhid intisarinya adalah sebagaimana tercermin dalam Surat Al-Fatihah. Pokok-pokoknya adalah: (1) Bahwa pencipta alam semesta yang sesungguhnya dialah satu-satunya yang menguasai alam dengan sedemikan rupa; 2) bahwa Allah Swt. telah memberikan nikmat yakni memberikan segala kebutuhan bagi makhluk-Nya, khususnya kepada manusia (3) Bahwa Allah Swt. adalah "raja" hari kemudian, dengan pengertian bahwa segala amal perbuatan manusia sewaktu di dunia ini akan diperhitungkan di sana; (4) Bahwa Allah Swt. adalah yang harus disembah dan satusatunya; (5) Bahwa Allah Swt. adalah penolong yang sebenarnya, oleh karenanya hanya kepadaNyalah manusia meminta pertolongan, bukan kepada yang selain-Nya; dan (6) Bahwa Allah Swt. sebenarnya yang membimbing dan memberi petunjuk kepada manusia. (Zuhairini, 2008:23).

Pertama-tama Muhammad Saw. dalam rangka memberikan pendidikan tauhid ini, mengajak umatnya untuk melihat sekeliling mereka. Rasul mengajarkan untuk membaca, melihat, memperhatikan, memahami kebesaran Allah Swt. dalam tiap diri manusia. Kemudian secara perlahan Rasul mengubah kebiasaan kaum kafir Quraisy pada saat itu misalnya ketika memulai melakukan pekerjaan tertentu biasanya mereka menyebut nama berhala kemudian diganti dengan bacaan basmalah, mengerjakan sesuatu niatnya karena Allah Swt., mengerjakan pekerjaan dengan harapan mendapatkan pertolongan dan petunjuk dari Allah Swt., tidak melanggar ketentuan Allah Swt. dan dalam segala perbuatan tercermin rasa kasih sayang.

2)Pengajaran al Qur'an

Selain ajaran tauhid, Rasul juga tidak melupakan ajaran tentang alquran. Ada beberapa faktor yang mengharuskan Nabi Muhammad untuk mengajarkan tentang alquran pada masyarakat Makkah secara sempurna. Kondisi masyarakat Arab pada saat itu masih belum bisa membaca dan menulis atau dikenal dengan istilah ummi, hanya segelintir orang saja yang bisa membaca dan menulis. Hal ini membuktikan bahwa baca tulis bukanlah kebiasaaan masyarakat Arab pada waktu itu. Pada awal permulaan Rasul datang ke Makkah hanya beberapa orang saja yang sudah mengenal baca tulis diantaranya: Umar bin Khattab, Ali bin Abu Thalib, Utsman bin Affan, Abu Ubaidah bin Al Jarah, dan lain-lain.

Materi pendidikan yang diberikan adalah materi baca tulis alquran, untuk saat ini dikenal dengan istilah imla' dan iqra'. Dengan diajarkannya materi ini diharapkan agar kebiasaan masyarakat Arab yang sering membaca syair-syair merdu (karena tradisi budaya lisan sangat kental pada masyarakat Arab saat itu) diganti dengan kebiasaan membaca alquran sebagai bacaan yang lebih tinggi nilai sastranya. Kemudian yang tidak kalah penting yakni materi menghafal ayat-ayat alquran. Dengan kebiasaan tradisi lisan masyarakat Arab yang kental, maka mereka dikenal kuat hafalannya.

Selanjutnya, untuk memantapkan hafalan mereka, Rasulullah Saw. sering mengadakan ulangan terhadap para sahabat-sahabatnya. Nabi Saw. menyuruh orang tersebut membaca ayat-ayat alquran di depannya agar mengetahui seberapa mampu dia menghafal ayat-ayat dan jika ada hafalan atau pengucapan yang salah akan langsung diperbaiki oleh Nabi saw. sendiri. Dalam bukunya yang berjudul Sejarah Pendidikan Islam, Mahmud Yunus (2002:78) menjelaskan bahwa pembinaan pendidikan Islam masa Makkah meliputi: 1) Pendidikan keagamaan yakni dengan ajaran membaca dengan nama Allah Swt. saja, dalam artian Tuhan hanya satu dan tidak bisa dipersekutukan dengan menyembah berhala, karena Allah Swt. Maha Besar dan Maha Pengasih sehingga berhala harus disingkirkan sejauh-jauhnya. 2) Pendidikan yang bersifat pengembangan akhlak dan ilmiah yaitu mempelajari kejadian manusia ketika diciptakan. Allah Swt. akan mengajarkan demikian itu kepada kaum-kaum yang memiliki niat untuk mempelajari dan membahasnya, sedangkan mereka dahulu belum mengetahuinya. Untuk mempelajari itu harus banyak membaca dan memahami. 3) Pendidikan akhlak dan budi pekerti, Nabi Muhammad saw. mengajar sahabatnya agar berakhlak baik sesuai dengan ajaran tauhid. 4) Pendidikan jasmani (kesehatan), yaitu mementingkan kebersihan pakaian, badan dan tempat tinggal. 


\section{b. Tahapan Pembinaan Pendidikan}

Perjalanan dakwah Nabi Muhammad SAW tentu jauh dari kata mulus. Banyak rintangan dan cobaan yang dilalui Rasulullah selama berdakwah. Bahkan penolakan berupa hinaan dan celaan dari Kafir Quraisy kerap beliau dapatkan.

1) Tahapan sembunyi-sembunyi

Dalam tiga tahun awal masa dakwahnya di Mekah, Rasulullah berdakwah dengan cara sembunyisembunyi. Ia mendakwahi beberapa orang terdekatnya yang diyakini bisa merahasiakan pesan yang dibawanya. Adapun mereka yang pertama masuk Islam pada periode ini adalah Abu Bakar AshShiddiq, Umar bin Khathab, Ustman bin Affan, Ali bin Abi Thalib, Thalhah bin 'Ubaidillah, Az-Zubair bin Al-Awwam, Abudurrahman bin Auf, Abu 'Ubaidah bin Al-Jarrah, Sa'ad bin Abi Waqqash, dan Said bin Zaid. Orang-orang ini kemudian mendapat julukan As-sabiqun Al-awwalun, yaitu orang-orang yang pertama masuk Islam. Nabi Muhammad terus melakukan dakwah secara sembunyi-sembunyi, sampai kemudian turun wahyu Allah SWT, Surat Al-Hijr ayat 94.

2) Tahapan terang-terangan

Setelah tiga tahun melakukan dakwah pendidikan Islam secara sembunyi-sembunyi, turunlah wahyu agar nabi Muhammad melakukan dakwah secara terang-terangan yang termaktub dalam Q.S. Al Hijr: 94 yang artinya: "Maka sampaikanlah (Muhammad) secara terang-terangan segala apa yang diperintahkan (kepadamu) dan berpalinglah dari orang-orang yang musyrik."

Perintah dakwah secara terangterangan ini seiring dengan semakin bertambahnya jumlah sahabat nabi Muhammad Saw. Nabi Muhammad kemudian melakukan dakwahnya secara terang-terangan. Nabi Muhammad menyediakan rumah Arqam bin Abil Arqam sebagai tempat pertemuan dengan paara sahabatnya. Beliau memulai dakwahnya dari Bani Hasyim, keluarga terdekatnya. Namun hanya Ali Bin Abi Thalib saja yang mau masuk Islam dan pamannya, Abu Thalib, bersedia membelanya walaupun ia belum mau mengucapkan syahadat. Banyak Kafir
Quraisy yang menentang ajaran Nabi Muhammad SAW, termasuk paman Nabi sendiri yaitu Abu Lahab. Mereka melakukan segala cara untuk menolak ajaran yang dibawa Rasulullah. Bahkan mereka berencana untuk membunuh Nabi Muhammad SAW.

Hingga akhirnya turun perintah Allah untuk hijrah ke Negeri Habasyah, di mana ada Raja yang adil di sana. Raja itu disebut-sebut tidak akan membiarkan rakyatnya ditindas dan dianiaya. Namun kemudian turun lagi perintah dari Allah untuk hijrah ke Kota Madinah. Kemudian Rasulullah beserta para sahabatnya hijrah ke Madinah dan membangun Masjid Quba. Masjid ini dijadikan sebagai tempat sholat dan tempat menyusun tugas-tugas dakwah. Pembangunan Masjid Quba berjalan dengan lancar dan Nabi Muhammad pun turut mengulurkan tangan dalam menyelesaikan pembangunannya. Rasulullah berdakwah sampai akhir hayatnya. Hingga akhirnya Rasulullah wafat pada hari Senin, 12 Rabiul Awal tahun 11 Hijriyah di usianya yang ke-63 tahun. Semua perjuangan Rasulullah telah membawa Islam dari jaman jahiliyah menuju peradaban Islam yang cerah.

\section{Pendidikan di Madinah}

Periode kedua adalah Periode Madinah, yaitu masa setelah Nabi Muhammad SAW hijrah ke Madinah dan menetap di sana hingga wafatnya beliau. Ada sejumlah ulama yang menandai periode ini dengan sebutan periode hijrah. Periode Madinah ini, yakni selama 9 tahun, 9 bulan, dan 9 hari. Ayat atau surat yang turun dalam periode ini kemudian dinamakan ayat atau surat Madaniyah. Namun, sebagian ulama Alquran, sebagaimana diuraikan oleh Nasr Hamid Abu Zaid dalam bukunya yang berjudul, Tekstualitas Alquran: Kritik Terhadap Ulumul Qur'an, ada yang bersikap berlebihan dalam membedakan aspek tempat ini. Mereka membuat klasifikasi khusus mengenai ayat apa saja yang diturunkan di antara Makkah dan Madinah dalam perjalananperjalanan Rasulullah SAW, ayat apa saja yang diturunkan setelah hijrah, sewaktu melakukan penaklukan, atau haji.

\section{Materi Pokok Pendidikan Islam}

Jika pada periode Makkah, corak pokok pembinaan pendidikan Islam lebih mengarah pada pendidikan tauhid (dalam arti yang luas), maka 
berbeda dengan periode Madinah. Pola yang diterapkan di Madinah lebih menekankan kepada pola pendidikan sosial-politik. Tetapi kedua ciri tersebut bukanlah dua hal yang bisa dipisahkan satu sama lain. Kalau pendidikan Islam di Makkah lebih menitikberatkan pada penanaman nilai-nilai tauhid ke dalam jiwa setiap individu Muslim. Sedangkan pembinaan pendidikan Islam di Madinah pada hakikatnya merupakan kelanjutan dari pendidikan tauhid di Makkah, yaitu pembinaan bidang pendidikan sosial-politik agar dijiwai ajaran tauhid, sehingga akhirnya tingkah laku sosial politiknya merupakan cermin dan pantulan sinar tauhid tersebut.

Perkembangan materi dan tujuan pendidikan Islam di Madinah semakin luas dibandingkan pendidikan Islam di Makkah. Hal ini diiringi dengan perkembangan masyarakat Islam dan petunjuk-petunjuk Allah. Tujuan pendidikan Islam bukan hanya difokuskan untuk membentuk pribadi kader Islam, namun masyarakat Madinah pada saat itu juga dibekali dengan pendidikan tauhid, akhlak, amal ibadah, kehidupan sosial kemasyarakatan dan keagamaan, ekonomi, kesehatan, bahkan kehidupan bernegara (Abudin, 2011:77-78).

Pada saat di Madinah, materi pendidikan yang diberikan cakupannya lebih kompleks dibandingkan dengan materi pendidikan fase Makkah. Materi pendidikan Islam itu antara lain: 1) Pendidikan persaudaraan sesama umat atau meningkatkan ukhuwah. Pada proses pelaksanaan pendidikan ukhuwah ini, Rasul saw. memfokuskan pada struktur kekeluargaan yang ada pada masa itu. Dalam usaha mempersatukan keluarga itu Nabi Muhammad saw. berusaha untuk mengikatnya menjadi satu kesatuan yang kuat. Masyarakat Madinah dipersaudarakan karena Allah Swt. bukan karena yang lain. Sesuai dengan Piagam Madinah bahwa antara orang yang beriman tidak boleh membiarkan saudaranya menanggung beban hidup dan utang yang berat di antara sesama manusia. 2) Pendidikan kesejahteraan sosial. Dalam hal ini Nabi Muhammad saw. selalu memberikan motivasi untuk selalu semangat mencari nafkah yang halal. Beliau mengarahkan kaum Muhajirin yang telah dipersaudarakan dengan kaum Anshar agar bekerjasama bahu membahu dalam mewujudkan masyarakat yang sejahtera. 3) Pendidikan kesejahteraan keluarga kaum kerabat. Nabi Muhammad saw. selalu berpesan agar memiliki ikatan kekerabatan yang solid satu sama lain. Selain itu, Rasul saw. berusaha untuk memperkenalkan dan sekaligus menerapkan sistem kekerabatan yang berdasarkan taqwa kepada Allah Swt. 4) Pendidikan Pertahanan dan Keamanan. Hal ini sangat penting bagi suatu peradaban yang sudah berdiri kokoh karena dengan adanya sistem keamanan dan pertahanan masyarakat pada saat itu mampu membentengi diri dari serangan musuh dari luar dengan membentuk pasukan dan tentara keamanan yang selalu siaga dalam menghadapi serangan musuh (Kamaruzzaman, 2007).

\section{KESIMPULAN}

Antara pendidikan Islam yang diajarkan oleh Nabi Muhammad Saw. di Makkah dan Madinah memiliki karakter, pola, dan perkembangannya yang berbeda. Jika di Makkah lebih kepada pengajaran pendidikan Islam yang menekankan pada pemahaman tauhid dan pengajaran alquran, sedangkan di Madinah lebih meluas cakupannya yakni selain diajarkan tauhid dan alquran, masyarakat Madinah dibekali dengan pendidikan akhlak, amal ibadah, kehidupan sosial kemasyarakatan dan keagamaan, ekonomi, kesehatan, bahkan kehidupan bernegara. Dalam proses perjalanannya Rasulullah saw. menerapkan pendidikan Islam disesuaikan dengan kondisi sosial masyarakat pada saat itu sehingga pendidikan Islam cepat diterima dan diamalkan oleh masyarakat Makkah dan Madinah.

\section{DAFTAR PUSTAKA}

Armanto. 2021. Filsafat Ilmu dalam dalam Perspektif Islam. Yogyakarta: K-Media

Latifah. 2019. Makna Isi Kandungan Surah AlA'raf Ayat 179 Dalam Konsep Dan Karakteristik Pendidikan Islam. Jurnal Terapung: Ilmu-Ilmu Sosial. Volume 2. Nomor 1 Maret 2020. eISSN: 2656-2928. https://ojs.uniska-

bjm.ac.id/index.php/terapung/article/view/2 929

Kamaruzzaman, 2007. Pola Pendidikan Islam Pada Periode Rasullulah: Makkah dan Madinah. Jakarta: Kencana Prenada Media Grup.

Kodir, Abdul. 2015. Sejarah Pendidikan Islam dari Masa Rasulullah hingga Reformasi di Indonesia. Bandung: Pustaka Setia.

Nata, Abuddin. 2011. Sejarah Pendidikan Islam, Jakarta: Kencana.

Noeng Muhajir. 1996. Metode Penelitian Kualitatif. Yogyakarta: Rakesarasih. 
Tafsir, Ahmad. 1994. Ilmu Pendidikan dalam Perspektif Islam, Bandung: Remaja Rosdakarya.

Zuhairini, dkk. 2008. Sejarah Pendidikan Islam, Jakarta: Bumi Aksara. 